\title{
An overview of the phenotypic and genotypic characteristics of multidrug-resistant Mycobacterium tuberculosis isolates from four Asian countries
}

Due to the HIV epidemic and the emergence of multidrug-resistant (MDR) strains, tuberculosis (TB) poses a public health threat globally after its initial decline decades ago. In Asia, the majority of TB patients live in highly populated countries such as India, China, Indonesia, the Philippines, Vietnam, Myanmar and Cambodia. In the year 2004, the World Health Organization estimated the TB incidence per 100000 of the population as 103 in Malaysia, 176 in Vietnam, 245 in Indonesia and 293 in the Philippines. Vietnam has the highest percentage $(2.3 \%)$ of drug-resistant cases as compared to the Philippines and Indonesia $(1.5 \%)$ and Malaysia (0.1\%) (WHO, 2006). Mortality is highest in the Philippines, with 48 deaths per 100000 of the population per annum, and coinfection of TB in HIV patients is becoming a growing concern in this part of the world (Iyawoo, 2004; WHO, 2006).

Timely diagnosis of both TB and MDR-TB is important for containing the disease. Diagnostic delay and improper treatment may lead to acquired drug resistance and increased transmission events as observed in Indonesia and elsewhere in the world (Anonymous, 1998; Streicher et al., 2004). The conventional method of drug susceptibility testing (DST) is timeconsuming, and standardization of the test for certain drugs poses a problem due to instability of the drugs in different culture media (Zanetti et al., 1997). Various liquid culture-based systems for assessment of drug resistance, such as the BACTEC 460 TB, MGIT 960 (Becton Dickinson), MB/ BACT System (bioMérieux), MB Redox (Biotest AG) and ESP Culture System II (AccuMed International), reduce the turnaround time to 1-2 weeks. However, these methods impose a considerable high running cost. It is now known that drug resistance in Mycobacterium tuberculosis is due to mutations in genes of the bacterium associated with specific drugs and that drugsensitive isolates lack these corresponding gene mutations (Johnson et al., 2006). This observation forms the basis for molecular detection of drug resistance by a variety of techniques. By using these methods, it has been shown that more than $90 \%$ of rifampicin-resistant clinical isolates have mutations in the $r p o B$ gene (van Rie et al., 2001). In addition, other fingerprinting methods, such as IS6110 RFLP and spoligotyping, have been used extensively to understand the strain dynamics in a given population (Kamerbeek et al., 1997; Streicher et al., 2004; van Embden et al., 1993; Victor et al., 1999).

This multicentre study focused on Indonesia, Malaysia, the Philippines and Vietnam, which have a high incidence of $\mathrm{TB}$ and where little is known about the variation in drug-resistant strains of $M$. tuberculosis. Standardized phenotypic and genotypic methods were used to give an overview of the characteristics of MDR isolates.

A total of 103 MDR M. tuberculosis isolates (resistant to at least rifampicin and isoniazid) originating from these four Asian countries, comprising 51, 22, 18 and 12 from the Philippines, Vietnam, Indonesia and Malaysia, respectively, were included in this study. These isolates were chosen from culture collections of each of the participating countries, dating from 1996 to 2006 . The isolates originated from government state-owned hospitals and private clinics of each of the countries. $M$. tuberculosis identification was confirmed by using the niacin and nitrate strips method (Indonesia, the Philippines and Vietnam) or the AccuProbe Culture Confirmation kit (GenProbe) (Malaysia). Phenotypic DST was carried out by the LJ proportional method (Indonesia and Vietnam), the LJ absolute concentration method (Malaysia) and by the disc submerged proportion method using
Middlebrook 7H10 agar (the Philippines). The following critical concentrations were used: $0.2 \mu \mathrm{g}$ and $1.0 \mu \mathrm{g}$ isoniazid $\mathrm{ml}^{-1}$, $1.0 \mu \mathrm{g}$ rifampicin $\mathrm{ml}^{-1}, 5.0 \mu \mathrm{g}$ ethambutol $\mathrm{ml}^{-1}$ and $2.0 \mu \mathrm{g}$ streptomycin $\mathrm{ml}^{-1}$. DNA templates for genotyping were prepared from scraped colonies in $400 \mu \mathrm{l}$ water and boiled for $30 \mathrm{~min}$. Drug-resistance genotyping was done by a probe-based method (Victor et al., 1999) and direct DNA sequencing, whereas spoligotyping (Kamerbeek et al., 1997) was used for strain differentiation.

About one-third of the isolates $(31.1 \%$ ) belonged to the Beijing strain family (Table 1). This finding was expected since it is known that the Beijing strain family dominates in Asian countries (Brudey et al., 2006). At the same time, the predominance of the EAI family $(39.8 \% ; 41 / 103)$ was evident in this study and most of these isolates (29 out of the 41) came from the Philippines (data not shown). The LAM family was present in the three countries except Vietnam (data not shown). Three of the isolates belonged to the Haarlem family, which is less-commonly seen in Asia (Brudey et al., 2006). Other known strain families that were less represented in this study included MANU, T and U. There were 15 isolates that could not be classified according to the international SpolDB4 database (Brudey et al., 2006).

Mutations in the cluster 1 region of the $r p o B$ gene that are commonly associated with rifampicin resistance were found in $91.3 \%(94 / 103)$ of the isolates. The majority of the isolates had mutations at codons 531 (53.4\%), $526(25.2 \%)$ and 516 (4.9\%). Two of the isolates had a double mutation (codons 511 and 512 and codons 531 and 516). Less-frequent mutations were identified at codons 513 and 522 . Isoniazid-resistance-related mutations in the $k a t G$ and $i n h A$ genes were detected in $77(74.8 \%)$ of the MDR isolates: 75 isolates had mutations in the kat $G$ gene 
Table 1. Specific mutations to rifampicin and isoniazid

\begin{tabular}{|c|c|c|c|c|c|c|c|}
\hline \multirow{3}{*}{$\begin{array}{l}\text { Genotype family } \\
\text { designation }\end{array}$} & \multirow{3}{*}{$\begin{array}{l}\text { Total number } \\
\text { of strains (\%) }\end{array}$} & \multicolumn{6}{|c|}{ Number of strains with resistance mutations } \\
\hline & & \multicolumn{4}{|c|}{ Rifampicin $[n=94(91.3 \%)]$} & \multicolumn{2}{|c|}{ Isoniazid $[n=77(74.8 \%)]$} \\
\hline & & rрoв 531 & rрoB 526 & rрoв 516 & Others & katG 315 & $\operatorname{inh} A-15$ \\
\hline EAI & $41(39.8)$ & 26 & 8 & 2 & 5 & 24 & 0 \\
\hline Beijing & $32(31.1)$ & 14 & 11 & 1 & 3 & 26 & 2 \\
\hline $\mathrm{U}$ & $5(4.9)$ & 3 & 1 & 1 & 0 & 5 & 0 \\
\hline LAM & $4(3.9)$ & 1 & 3 & 0 & 0 & 2 & 0 \\
\hline Haarlem & $3(2.9)$ & 2 & 0 & 0 & 0 & 2 & 0 \\
\hline $\mathrm{T}$ & $2(1.9)$ & 0 & 0 & 1 & 0 & 2 & 0 \\
\hline Manu2 & $1(1.0)$ & 0 & 0 & 0 & 0 & 1 & 0 \\
\hline Unclassified & 15 (14.6) & 9 & 3 & 0 & 2 & 13 & 0 \\
\hline Total & 103 & $55(53.4 \%)$ & $26(25.2 \%)$ & $5(4.9 \%)$ & $10(9.7 \%)$ & $75(72.8 \%)$ & $2(1.9 \%)$ \\
\hline
\end{tabular}

codon 315 and only 2 isolates had mutations in the inhA promoter region. There was no correlation between mutation pattern and spoligotype in this study. Further studies need to be done in each of these countries to provide an indepth characterization of MDR-TB. The correlation between drug resistance gene mutations and phenotypic resistance is congruent with what has been published (van Rie et al., 2001). The rpoB gene, specifically the rifampicin resistancedetermining region, remains a good marker for rapid diagnosis of MDR-TB and can be incorporated into the current MDR-TB detection strategies in TB control.

\section{Acknowledgements}

The authors would like to acknowledge IAEA for the financial support and the Department of Biomedical Sciences, Stellenbosch University, for the use of the facilities for all the molecular work. Thanks to Ms Adilah Zirwatul, Ms Wilma Bulatao, Mr Van Hung Nguyen and $\mathrm{Ms}$ Ngoc Lan Nguyen for providing the isolates and to Dr Sang-Nae Cho for his kind assistance.

\section{F. Ang, ${ }^{1}$ C. S. Ong, ${ }^{2}$ A. Rukmana, ${ }^{3}$}

K. L. Pham Thi, ${ }^{4}$ S. F. Yap, ${ }^{2}$

Y. F. Ngeow, ${ }^{5}$ M. L. Ho, ${ }^{4}$ T. M. Sudiro, ${ }^{3}$

B. Bela, ${ }^{3}$ A. M. Jordaan, ${ }^{6}$

E. M. Streicher ${ }^{6}$ and T. C. Victor ${ }^{6}$

${ }^{1}$ Infectious Disease Section, Medical Research Laboratory, Department of Medicine, University of the Philippines, Philippine General Hospital, Manila, The Philippines
${ }^{2}$ Faculty of Information Science and Technology, Multimedia University, Malacca, Malaysia

${ }^{3}$ Department of Microbiology, Medical Faculty, University of Indonesia, Jakarta, Indonesia

${ }^{4}$ Department of Bacteriology, National Institute of Hygiene and Epidemiology, Hanoi, Vietnam

${ }^{5}$ National Public Health Laboratory, Selangor, Malaysia

${ }^{6}$ DST/NRF Centre of Excellence in Biomedical TB Research, MRC Centre for Molecular and Cellular Biology, Department of Biomedical Sciences, Division of Molecular Biology and Human Genetics, Faculty of Health Sciences, Stellenbosch University, Tygerberg, South Africa

Correspondence: C. S. Ong

(chiasui@gmail.com)

Anonymous (1998). TB second highest killer in Indonesia. Aust Nurs J 5, 15.

Brudey, K., Driscoll, J. R., Rigouts, L., Prodinger, W. M., Gori, A., Al-Hajoj, S. A., Allix, C., Aristimuno, L., Arora, J. \& other authors (2006). Mycobacterium tuberculosis complex genetic diversity: mining the fourth international spoligotyping database (SpolDB4) for classification, population genetics and epidemiology. BMC Microbiol 6, 23.

lyawoo, K. (2004). Tuberculosis in Malaysia: problems and prospect of treatment and control. Tuberculosis (Edinb) 84, 4-7.

Johnson, R., Streicher, E. M., Louw, G. E., Warren, R. M., van Helden, P. D. \& Victor, T. C. (2006). Drug resistance in Mycobacterium tuberculosis. Curr Issues Mol Biol 8, 97-111.
Kamerbeek, J., Schouls, L., Kolk, A., van Agterveld, M., van Soolingen, D., Kuijper, S., Bunschoten, A., Molhuizen, H., Shaw, R. \& other authors (1997). Simultaneous detection and strain differentiation of Mycobacterium tuberculosis for diagnosis and epidemiology. J Clin Microbiol 35, 907-914.

Streicher, E. M., Warren, R. M., Kewley, C., Simpson, J., Rastogi, N., Sola, C., van der Spuy, G. D., van Helden, P. D. \& Victor, T. C. (2004). Genotypic and phenotypic characterization of drug-resistant Mycobacterium tuberculosis isolates from rural districts of the Western Cape province of South Africa. J Clin Microbiol 42, 891-894.

van Embden, J. D. A., Cave, M. D. \& Crawford, J. T. (1993). Strain identification of Mycobacterium tuberculosis by DNA fingerprinting: recommendation for a standardized methodology. J Clin Microbiol 31, 406-409.

van Rie, A., Warren, R., Mshanga, I., Jordaan, A. M., van der Spuy, G. D., Richardson, M., Simpson, J., Gie, R. P., Enarson, D. A. \& other authors (2001). Analysis for a limited number of gene codons can predict drug resistance of Mycobacterium tuberculosis in a high-incidence community. J Clin Microbiol 39, 636-641.

Victor, T. C., Jordaan, A. M., van Rie, A., van der Spuy, G. D., Richardson, M., van Helden, P. D. \& Warren, R. (1999). Detection of mutations in drug resistance genes of Mycobacterium tuberculosis by a dot-blot hybridization strategy. Tuber Lung Dis 79, 343-348.

WHO (2006). Global Tuberculosis control: Surveillance, Planning, Financing. Geneva: World Health Organization (WHO/HTM/TB/ 2006.362)

Zanetti, S., Ardito, F., Sechi, L., Sanguinetti, M., Molicotti, P., Delogu, G., Pinna, M. P., Nacci, A. \& Fadda, G. (1997). Evaluation of nonradiometric system (BACTEC $9000 \mathrm{MB}$ ) for detection of mycobacteria in human clinical samples. J Clin Microbiol 35, 2072-2075. 